Historic, Archive Document

Do not assume content reflects current scientific knowledge, policies, or practices. 


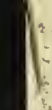




\section{Have You Seen This Beetle?}

$\mathbf{H}$ detect the Asian longhorned beetle and other woodboring pests by inspecting solid wood packing material from China, including Hong Kong, in your warehouse. For positive identification of insect specimens, contact your local USDA-Animal and Plant Health Inspection Service, Plant Protection and Quarantine, office or your State's plant health director. If you need additional information, call (301) 734-5255 or visit the Asian longhorned beetle Website at http://www.aphis.usda.gov/oa/alb/alb.html
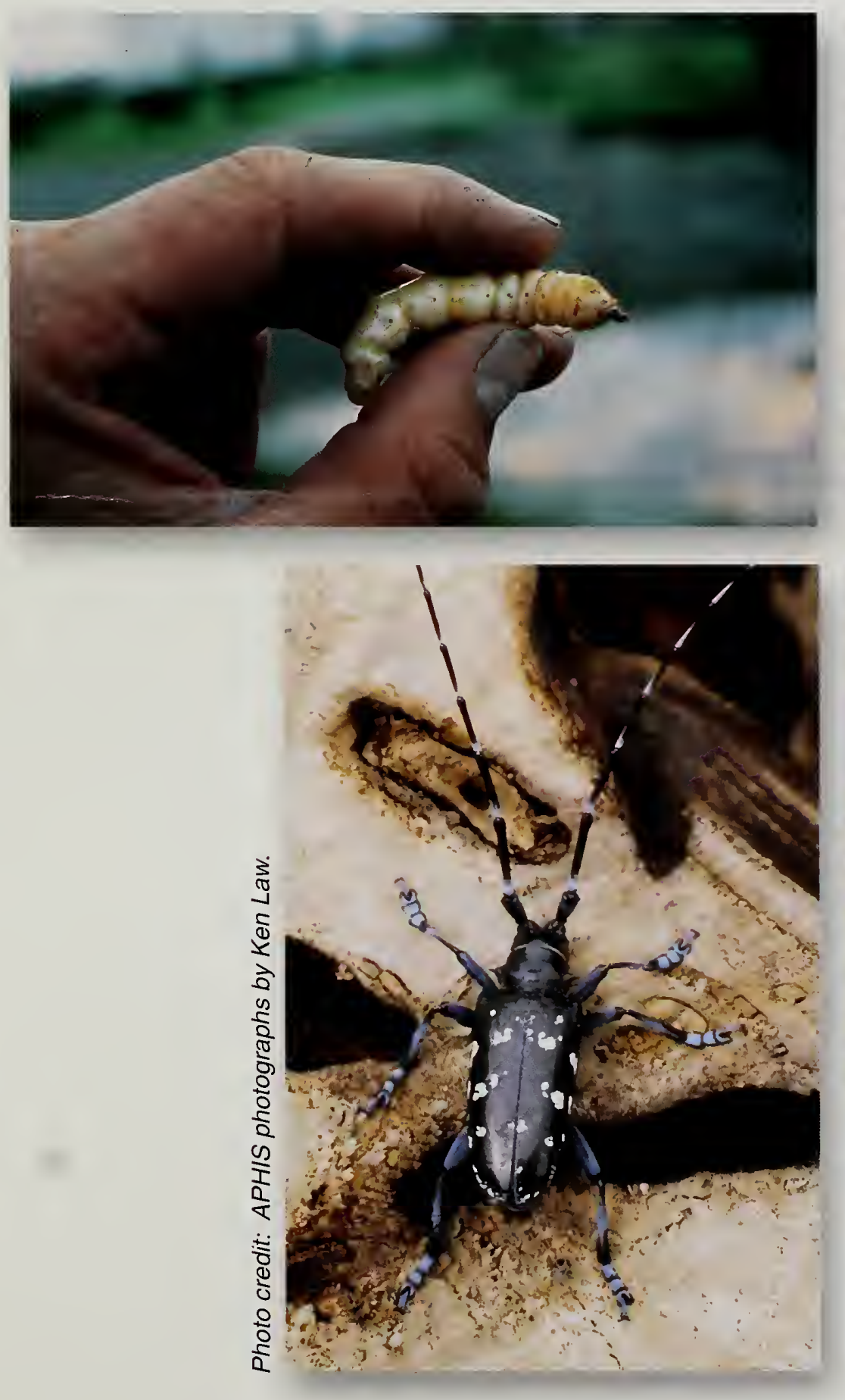

The body of this pest is about an inch long, shiny, and black with bright white spots. Its curved black antennae with white rings are even longer than its body.

Check wooden crates and pallets fokexit or entry holes, larvae, sawdust and other ingect aste, and live beetles.

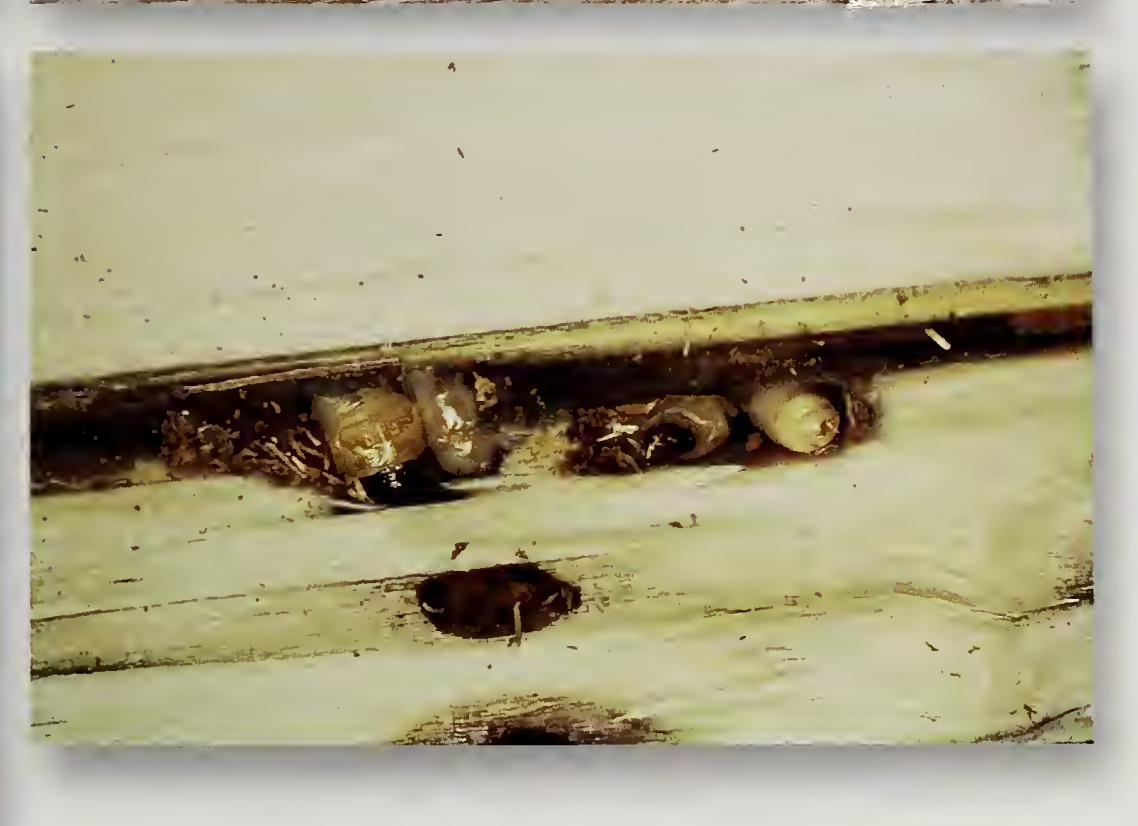

\section{USDA}

U.S. Department of Agriculture

Animal and Plant Health Inspection Service

Program Aid No. 1663

Issued September 1999

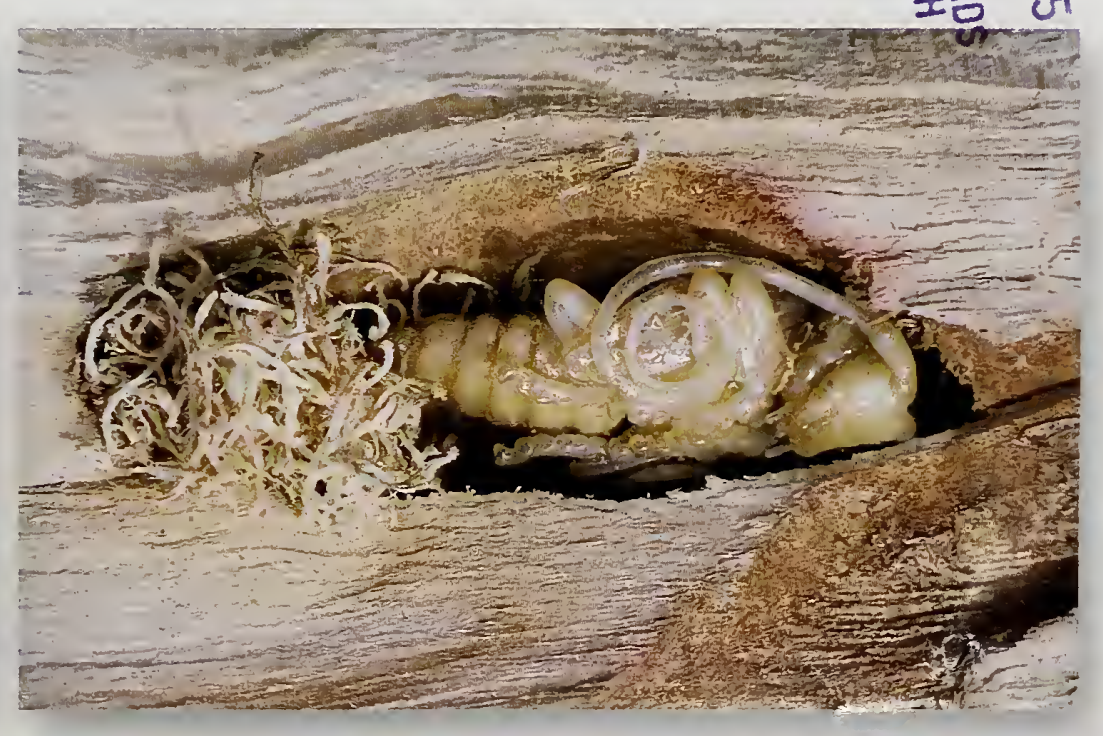


